\title{
Blockchain and the Economics of Food Safety
}

\section{By: Nir Kshetri}

Kshetri, Nir (2019)."Blockchain and The Economics of Food Safety" IEEE IT Professional, 21(3) 63-66. https://doi.org/10.1109/MITP.2019.2906761

(C) 2019 IEEE. Personal use of this material is permitted. Permission from IEEE must be obtained for all other uses, in any current or future media, including reprinting/republishing this material for advertising or promotional purposes, creating new collective works, for resale or redistribution to servers or lists, or reuse of any copyrighted component of this work in other works.

\begin{abstract}
:
Blockchain technology has a potential to address many of the food safety challenges facing the world today. Some of the most promising blockchain applications developed to data have been in the food supply chains.
\end{abstract}

Keywords: blockchain | supply chains | economics | food safety | food industry

\section{Article:}

Adulterated, contaminated, mislabeled, and misbranded food products have imposed tremendous social and economic costs to the global economy. About 600 million people in the world become ill due to contaminated food every year. Of those, about 420000 die, which include 125000 children under the age of 5 years. ${ }^{1}$ According to a study conducted by the World Bank, unsafe food products cost low- and middle-income economies $\$ 110$ billion in lost productivity and medical expenses annually (https://www.foodsafetynews.com/2018/10/unsafe-food-in-lmicscosts-110-billion-a-year-world-bank/). One estimate suggested that $30 \%-40 \%$ of the food consumers eat is either "adulterated or mislabeled" (http://www.connect.catalystinc.org/techwatch/arcnet). In a survey, 39\% of food manufacturers thought that their products can be easily counterfeited, and $40 \%$ viewed that food fraud is difficult to detect using the currently available methods (https://www.nzherald.co.nz/business/news/article.cfm?c id=3\&objectid=12039985).

Food safety is of particular concern in industrialized countries where consumers are increasingly demanding higher quality and safer food. ${ }^{2}$ A study conducted at the household level in the U.S. found that inadequate quality of food products is one of the key sources of food insecurity. ${ }^{3}$

There is big hope that blockchain technology can address many of the food safety challenges facing the world today. ${ }^{4}$ Indeed, some of the most promising blockchain applications outside finance are being developed to address various concerns in the food supply chains (http://internetofthingsagenda.techtarget.com/blog/IoT-Agenda/Blockchain-for-industrialenterprises-Hype-reality-obstacles-and-outlook). 
At the national level, there is a tremendous positive economic impact of safe and quality food products associated with better health outcomes of citizens. At the firm level, companies in the food supply chains can use blockchain to address problems related to inefficiency, opacity, and fraud. Blockchain is also being used by some firms in the food industry to enhance reputational value by demonstrating their ability to innovate. ${ }^{5}$

\section{Some Blockchain Projects in Food Supply Chains}

A number of firms in the food industry have started to incorporate blockchain in supply chains (see Table 1). In November 2018, IBM commercially launched its blockchain-based Food Trust. Companies of all sizes in the food industry supply chain can join the network for a subscription fee that ranges from $\$ 100$ to $\$ 10000$ a month (https://hawthorncaller.com/ibms-foodblockchain-is-going-live-with-a-supermarket-giant-on-board/). IBM Food Trust is being used by many large food companies such as Nestle, Unilever, and Walmart.

Table 1. Blockchain deployment in food supply chains: Some examples.

\begin{tabular}{|c|c|c|}
\hline Food retailer & Explanations & Remarks \\
\hline $\begin{array}{l}\text { U.S. retailer } \\
\text { Walmart }\end{array}$ & $\begin{array}{l}\text { 2016: Trial-tested a blockchain-based } \\
\text { solution to monitor pork products in China } \\
\text { and produce imported to the U.S. from Latin } \\
\text { America (https://classic.qz.com/perfect- } \\
\text { company-2/1146289/the-worlds-biggest- } \\
\text { retailer-wants-to-bring-blockchains-to-the- } \\
\text { food-business). }\end{array}$ & $\begin{array}{l}\text { Blockchain enabled the tracking of pork products in a few } \\
\text { minutes compared to many days taken in the past. Details } \\
\text { about the farm, factory, batch number, storage temperature, } \\
\text { and shipping can be viewed on blockchain } \\
\text { (http://www.foodsafetynews.com/2017/03/a-new-era-of-food- } \\
\text { transparency-with-wal-mart-center-in- } \\
\text { china/\#.WOB65mcVjIU). }\end{array}$ \\
\hline $\begin{array}{l}\text { French retailer } \\
\text { Carrefour }\end{array}$ & $\begin{array}{l}\text { Signed an agreement with IBM to use the } \\
\text { solution }\end{array}$ & $\begin{array}{l}\text { Announced a plan to track its own branded products in France, } \\
\text { Spain, and Brazil. It also noted plans to expand to other } \\
\text { countries by } 2022 \text { (https://hawthorncaller.com/ibms-food- } \\
\text { blockchain-is-going-live-with-a-supermarket-giant-on-board/). }\end{array}$ \\
\hline $\begin{array}{l}\text { Chinese e- } \\
\text { commerce } \\
\text { company } \\
\text { Jingdong } \\
\text { (JD.com) }\end{array}$ & $\begin{array}{l}\text { Implemented blockchain in food supply } \\
\text { chains system, mainly involving B2B e- } \\
\text { commerce. }\end{array}$ & $\begin{array}{l}\text { 2017: Its blockchain system went live with inner Mongolia- } \\
\text { based food supplier Kerchin as its first supply-chain partner } \\
\text { (Kshetri and Loukojanova, 2019). }{ }^{6} \text { Kerchin collects and stores } \\
\text { data in its supply chain by scanning barcodes of its products. } \\
\text { The information is then entered onto blockchain. After that, } \\
\text { any changes in data require a digital signature. Both parties are } \\
\text { informed if there is any change and modification in the data. }\end{array}$ \\
\hline $\begin{array}{l}\text { U.S.-based } \\
\text { Bumble Bee } \\
\text { Foods }\end{array}$ & $\begin{array}{l}\text { March 2019: Announced the launch of a } \\
\text { blockchain platform to trace seafood. The } \\
\text { company teamed up with German } \\
\text { technology company SAP for the project } \\
\text { (https://cointelegraph.com/news/north- } \\
\text { american-seafood-firm-to-use-blockchain- } \\
\text { tech-in-supply-chain). }\end{array}$ & $\begin{array}{l}\text { By scanning a QR code on the product package, consumers } \\
\text { would be able to access information related to the details of the } \\
\text { supply chain such as products' origins, the size of the catch, } \\
\text { the point of capture shipping history, and trade fishing } \\
\text { certification. }\end{array}$ \\
\hline
\end{tabular}

The French retailer Carrefour has been one of the early adopters of the IBM Food Trust (see Table 1). The retailer announced in March 2019 that it would launch blockchain-enabled QRcodes for some of its milk products. With a smartphone app, customers can scan the labels to learn details about milk products that they buy. The labels provide relevant details such as the date and location of collection and packaging of a milk package, the GPS coordinates of dairy farm producing it, and how the cow was fed (https://thenextweb.com/hardfork/2019/03/06/carrefour-blockchain-milk/). 
Big food retailers are also forcing their suppliers to adopt blockchain. In September 2018, Walmart announced that it would require its suppliers of leafy green vegetables to upload their data to the blockchain system by September 2019 (https://techcrunch.com/2018/09/24/walmartis-betting-on-the-blockchain-to-improve-food-safety/).

Firms in food supply chains are rapidly adopting blockchain systems. Examples from retailers such as Carrefour indicate that blockchain can be used to provide access to rich and detailed information about food products, which is likely to reduce uncertainty about quality and ingredients. This will increase consumers' confidence in food products that they buy. Food companies, thus, can boost revenue and profits by using blockchain.

For food retailers, another key benefit of blockchain is its ability to effectively handle a crisis situation. To illustrate this argument, consider the 2015 E.coli outbreak at Chipotle Mexican Grill outlets. The crisis left 55 customers ill. There were many negative news stories about this foodborne illness. Many Chipotle restaurants were shut down, and investigations took place. All these led to a significant blow to the reputation of the company. There was a dramatic reduction in sales revenues. The company's share price dropped by $42 \%$. The roots of the problem lie partly in Chipotle's reliance on multiple suppliers. Companies such as Chipotle cannot monitor their suppliers in real time. It is, thus, impossible to prevent food contaminations. It is also difficult to contain a food crisis in a targeted way after it is discovered (https://hbr.org/2017/03/global-supply-chains-are-about-to-get-better-thanks-to-blockchain). Chipotle's value proposition is centered on fresh and locally sourced ingredients. Food supply chain systems based on nonblockchain methods are expensive and cumbersome. The process involves manual verification and massive record keeping. Blockchain can reduce the workload and ensure traceability.

\section{Some Key Challenges}

While the various benefits of blockchain in food supply chains cannot be disputed, it is also important to look on the cost sides. The high cost of hiring blockchain developers leads to adverse economics of blockchain deployment in this industry. For instance, according to the job data analytics firm Burning Glass Technologies, the median annual salary for a fulltime blockchain developer in the U.S. was $\$ 140000$ in 2018, compared to \$105000 for general software developers. Blockchain specialists are reported to charge as much as $\$ 250$ per hour. ${ }^{8}$

Labor and skill shortages have been identified as a key challenge in the blockchain industry. The shortage is especially severe in developing economies. ${ }^{9}$ For instance, out of the country's 2 million software developers, only 5000 were estimated to have blockchain skills. Some speculate that about $80 \%$ of these developers may pursue job opportunities outside the country. ${ }^{10}$

Due primarily to the high costs and limited availability of blockchain talents, currently, the deployment of blockchain-based solutions is more justifiable and more realistic in high-value food products than in cheaper products. ${ }^{4}$ For instance, in 2018, JD.com announced a plan to implement blockchain to track its meat supply chains. Customers would be able to monitor their meat products. Initial focus would be on high-end beef from Australia 
(https://tinyurl.com/y8kfyv75). Likewise, the French retailer Carrefour 's traceability project focused on its premium farm products (https://www.ledgerinsights.com/oxfam-blockchaincambodian-rice-farmers/).

A related point is that only big firms in the food supply chains are currently in a position to implement blockchain-based solutions. For instance, JD's SC partner Kerchin that has adopted blockchain had $\$ 300$ million in revenue in $2017 .{ }^{7}$ Most of the food products in developing economies such as Africa and China, on the other hand, are produced by very small farms. These farms lack access to technology or Internet connectivity. Adoption of blockchain systems can be unrealistic for these farms, at least in the near future.

\section{Summary}

Blockchain systems can bring transparency and accountability in food supply chains. Such systems, thus, are likely to play a tremendously important role in ensuring food safety. Global economic and health benefits of blockchain systems' deployment to trace food products are, thus, extremely high.

Firms in the food industry can significantly enhance customer loyalty and sales growth by using blockchain. For firms in the food industry, it is also important to be able to handle crisis situations in order to be profitable. Blockchain-based solutions can help deal with risk situations involving crises and emergencies. For instance, if contaminated food products are found, food retailers can easily identify the source and engage in strategic removals of affected products. They do not need to recall the entire product line.

While the benefits of blockchain systems in food supply chains outweigh the costs on average, such systems are currently out of reach for most small firms in the food industry. The solutions already available hold the promise of developing cheaper systems that are easier to use and trust-for farmers, food processing plants, and customers alike. Over time, blockchain implementation costs in the food industry are likely to reduce. This is likely to make blockchainbased solutions more affordable to smaller companies and accelerate its diffusion in food supply chains.

\section{REFERENCES}

1. World Health Org., "More than 23 million people in the WHO European region fall ill from unsafe food every year," 2015. [Online]. Available: http://www.euro.who.int/en/healthtopics/disease-prevention/food-safety/news/news/2015/12/more-than-23-million-people-inthe-who-european-region-fall-ill-from-unsafe-food-every-year

2. J. Kinsey, "GATT and the economics of food safety," Food Policy, vol. 18, no. 2, pp. 163176, Apr.1993. [Online].

Available: https://www.sciencedirect.com/science/article/abs/pii/0306919293900246

3. P. Webb, J. Coates, E. Frongillo, B. Rogers, A. Swindale, and P. Bilinsky, "Measuring household food insecurity: Why it's so important and yet so difficult to do," J. Nutrition, vol. 
136, no. 5, pp. 1404S-1408S, 2006. [Online].

Available: https://academic.oup.com/jn/article/136/5/1404S/4670058

4. N. Kshetri, "Blockchain systems are tracking food safety and origins," Nov. 21,2018. [Online]. Available: https://theconversation.com/blockchain-systems-are-tracking-foodsafety-and-origins-106491

5. M. Higginson, M. Nadeau, and K. Rajgopal, “Blockchain's Occam problem,” Jan.2019. [Online]. Available: https://www.mckinsey.com/industries/financial-services/ourinsights/blockchains-occam-problem?cid=other-eml-alt-mipmck\&hlkid=f1 ff7216a70e4041951d60293978a0ea\&hctky=2762145\&hdpid=95e9bdfa-07094b4d-8252-f401bcaac86d

6. N. Kshetri and E. Loukoianova, "Blockchain adoption in supply chain networks in Asia," IEEE IT Profess., vol. 21, no. 1, pp. 11-15, Jan./Feb.2019.

7. E. Huang, "Blockchain could fix a key problem in China's food industry: The fear of food made in China," 2017. [Online]. Available: https://qz.com/1031861/blockchain-could-fix-akey-problem-in-chinas-food-industry-the-fear-of-food-made-in-china/

8. L. Mearian, "Blockchain moves into top spot for hottest job skills," May 1,2018. [Online]. Available: https://www.computerworld.com/article/3235972/blockchain-moves-into-topspot-for-hottest-job-skills.html

9. N. Kshetri, "The Indian blockchain landscape: Regulations and policy measures," Asian Res. Policy, vol. 9, no. 2, pp. 56-71, 2018.

10. M. Agarwal, "Blockchain: India likely to see brain drain as $80 \%$ developers may move abroad," 2018. [Online]. Available: https://inc42.com/buzz/blockchain-india-likely-to-sufferbrain-drain-as-80-developers-prepare-to-move-abroad/

Nir Kshetri is a Professor of management with the Bryan School of Business and Economics, University of North Carolina at Greensboro. Contact him at nbkshetr@uncg.edu. 